\title{
The role of yogurt in the diets of the Irish population (5-90y)
}

\author{
R. McCarthy ${ }^{1}$, L. Kehoe ${ }^{1}$, J. Walton ${ }^{1}$, B.A. McNulty ${ }^{2}$, A.P. Nugent ${ }^{2}$ and A. Flynn ${ }^{1}$ \\ ${ }^{1}$ School of Food and Nutritional Sciences, University College Cork, Republic of Ireland and \\ ${ }^{2}$ UCD Institute of Food and Health, University College Dublin, Belfield, Dublin 4, Republic of Ireland
}

Yogurt is a nutrient dense food from the dairy category which provides an array of important nutrients to the diet ${ }^{(1)}$. The healthy eating guidelines in Ireland recommend the following number of servings of dairy per day: for children aged 5-13 years; 3 servings, $14-18 \mathrm{y} ; 5$ servings, females $>19 \mathrm{y} ; 3$ servings, males $19-50 \mathrm{y} ; 3-5$ servings and males $>51 \mathrm{y} ; 3$ servings ${ }^{(2)}$. One carton $(125 \mathrm{~g})$ of yogurt is equivalent to one serving of dairy ${ }^{(3)}$. The objective of this analysis was to estimate the intake of yogurt $(\mathrm{g} / \mathrm{d}$, contribution to dairy servings) in the Irish population and to investigate the contribution of yogurt to energy and selected nutrient intakes by age-group. Analyses were based on data collected from three nationally representative surveys in the Irish population; the National Children's Food Survey (NCFS) of 5-12 year olds (2003-04), the National Teens' Food Survey (NTFS) of 13-17 year olds (2005-06) and the National Adult Nutrition Survey (NANS) of adults 18-90 year olds (2008-10) (www.iuna.net). In all surveys, dietary intake data were collected using food diaries (NCFS; 7d weighed, NTFS; 7d semi-weighed and NANS; 4d semi-weighed). Nutrient intakes were estimated using WISP based on McCance and Widdowson's The Composition of Foods $6^{\text {th }}$ edition $^{(4)}$ and the Irish food composition database ${ }^{(5)}$. The nutritional composition of yogurts was updated to reflect the current (2017) composition of this food group. The table below presents the mean daily intake (MDI) of yogurt (g/d) and the contribution (\%) of yogurt to intake of energy and selected nutrients by age group in consumers only.

\begin{tabular}{|c|c|c|c|c|c|c|}
\hline Age group & $\begin{array}{c}5-12 y \\
n=384\end{array}$ & $\begin{array}{l}13-17 y \\
n=170\end{array}$ & $\begin{array}{c}18-25 y \\
n=76\end{array}$ & $\begin{array}{l}26-35 y \\
n=124\end{array}$ & $\begin{array}{l}36-55 y \\
n=225\end{array}$ & $\begin{array}{c}>55 \mathrm{y} \\
\mathrm{n}=189\end{array}$ \\
\hline Consumers (\%) & 65 & 39 & 32 & 42 & 40 & 47 \\
\hline MDI (g/d) & 50 & 49 & 60 & 73 & 74 & 87 \\
\hline \multicolumn{7}{|c|}{ Contribution (\%) of yogurt to mean daily intake of energy and selected nutrients (in consumers only) } \\
\hline Energy & $2 \cdot 6$ & 1.9 & 2.4 & $2 \cdot 8$ & $3 \cdot 0$ & $4 \cdot 0$ \\
\hline Protein & $3 \cdot 5$ & $2 \cdot 3$ & $3 \cdot 0$ & $3 \cdot 2$ & 3.5 & $4 \cdot 2$ \\
\hline Carbohydrate & $2 \cdot 6$ & $2 \cdot 1$ & $2 \cdot 9$ & $3 \cdot 6$ & $3 \cdot 8$ & 4.5 \\
\hline Total Sugar & 5.4 & $4 \cdot 8$ & $6 \cdot 1$ & $8 \cdot 1$ & $9 \cdot 3$ & 9.9 \\
\hline Free Sugar & - & - & $8 \cdot 2$ & 11.4 & $15 \cdot 0$ & $15 \cdot 9$ \\
\hline Total Fat & 1.8 & $1 \cdot 2$ & 1.8 & $2 \cdot 0$ & $2 \cdot 2$ & $3 \cdot 4$ \\
\hline Saturated Fat & $2 \cdot 7$ & $2 \cdot 0$ & 3.0 & $3 \cdot 2$ & $3 \cdot 5$ & $5 \cdot 5$ \\
\hline Dietary Fibre & $1 \cdot 1$ & $0 \cdot 9$ & $1 \cdot 3$ & 1.7 & 1.6 & $2 \cdot 0$ \\
\hline Sodium & 1.0 & $0 \cdot 9$ & $1 \cdot 1$ & $1 \cdot 1$ & $1 \cdot 3$ & 1.6 \\
\hline Potassium & $5 \cdot 7$ & $2 \cdot 8$ & $3 \cdot 7$ & $4 \cdot 1$ & $4 \cdot 3$ & $5 \cdot 1$ \\
\hline Calcium & 7.9 & $6 \cdot 9$ & $9 \cdot 5$ & $10 \cdot 2$ & $10 \cdot 8$ & 11.8 \\
\hline Vitamin B2 & $8 \cdot 5$ & $4 \cdot 6$ & $6 \cdot 1$ & $6 \cdot 6$ & $7 \cdot 6$ & $8 \cdot 8$ \\
\hline Vitamin B12 & $6 \cdot 9$ & $3 \cdot 0$ & $4 \cdot 0$ & $4 \cdot 4$ & 4.9 & $5 \cdot 1$ \\
\hline Vitamin D & $23 \cdot 2$ & $14 \cdot 4$ & $5 \cdot 5$ & $4 \cdot 7$ & $3 \cdot 8$ & $3 \cdot 1$ \\
\hline
\end{tabular}

- No data currently available for free sugar composition for NCFS and NTFS surveys.

The percent of yogurt consumers in Ireland ranges from 32-65\% across population groups. Among consumers, yogurt contributes $0.4-0.7$ servings of dairy per day. Relative to its contribution to energy intake (2-4\%), yogurt is a nutrient dense dairy food contributing similar proportions of protein, carbohydrate and fat (total and saturated) and a greater proportion of sugars (total and free) potassium, calcium, vitamin B2, vitamin B12 and vitamin D. Increased intakes of yogurt with lower free sugar content are needed to help meet recommended servings of dairy.

The study was funded by Danone (UK and Ireland) and the National Dietary Surveys were funded by the Irish Department of Agriculture, Food and the Marine.

1. McKinley CM (2005) Int J Dairy Technol, 58 (1), 1

2. Food Safety Authority of Ireland (2011) FSAI. Dublin, Ireland.

3. Healthy Ireland (2016) Department of Health. Dublin, Ireland.

4. Food Standards Agency (2002) Royal Society of Chemistry. Cambridge.

5. Black LJ, Ireland J, Moller A et al. (2011) J Food Compos and anal, 24 (7), 1017-1023. 